\title{
Commentary: Purulence in the heart of a child? This should not be
}

\author{
Ronald K. Woods, MD, PhD
}

From the Division of Pediatric Cardiothoracic Surgery, Department of Surgery, Medical College of Wisconsin, Milwaukee, Wis; and Herma Heart Institute, Children's Hospital of Wisconsin, Milwaukee, Wis. Disclosures: Woods is cofounder of OperVu, Inc, which has no relationship to the content of this work.

Received for publication June 17, 2019; accepted for publication June 18, 2019; available ahead of print July 29, 2019.

Address for reprints: Ronald K. Woods, MD, PhD, Division of Pediatric Cardiothoracic Surgery, Department of Surgery, Medical College of Wisconsin, Children's Hospital of Wisconsin, 9000 W Wisconsin Ave, MS B 730, Milwaukee, WI 53226 (E-mail: rwoods@chw.org).

J Thorac Cardiovasc Surg 2019;158:1410

$0022-5223 / \$ 36.00$

Copyright (c) 2019 by The American Association for Thoracic Surgery

https://doi.org/10.1016/j.jtcvs.2019.06.071

In this issue of the Journal, Khoo and colleagues, ${ }^{1}$ the group from Melbourne, report their surgical experience with a large cohort of pediatric patients with infective endocarditis (IE) spanning the interval 1987 to 2017 . They organized and analyzed a tremendous amount of data, including all forms of IE. They report a variety of interesting results, which need not be reiterated in a commentary. I found 2 main points more interesting: (1) mechanical valve replacement was done in only 3 of 39 aortic valves and in only 5 of 37 mitral valves (this is a bit more intuitive for me); and (2) the estimated 25-year freedom from recurrent IE was $95 \%$ - an impressive result, even if many of these valves were not subject to 25 years of risk. For aortic valves, 16 of 39 valves were actually repaired, 12 were replaced with pulmonary autografts, and 8 were replaced with homografts. The reoperative burden of the overall cohort was not trivial, but this is consistent with valve surgery in growing children. I offer only one critique of their results. The normalized vegetation size is intuitively appealing; however, it was based on data for only $43 \%$ of patients. As is true for many reports of pediatric IE, the results of the report of Khoo and colleagues, ${ }^{1}$ although good and interesting, are not likely to affect guidelines or change how we manage this disease.

The principles of surgery for IE are pretty simple-get rid of the disease and provide an arrangement for good structure and function of the heart. It is when the surgeon must decide exactly how to achieve these goals in a specific child that things can get complicated. I do not offer the pretense of insignificance of right-sided disease, nor the lack of complexity inherent in repair of diseased mitral valves; however, it is my impression that the aortic valve poses unique challenges, particularly in younger, growing children. Valvular insufficiency, which is typical, introduces special challenges. If the child's condition is unstable,

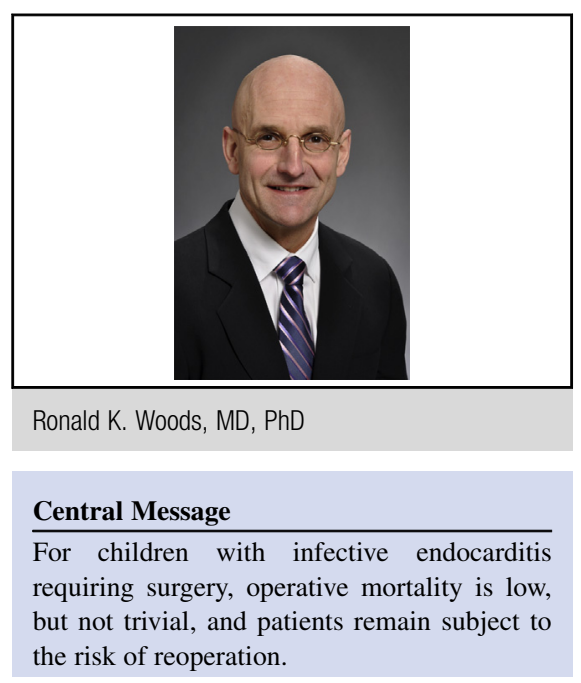

See Article page 1399. customary measures of preoperative stabilization, such as extracorporeal life support, are not a meaningful option. If it is a resternotomy, and fibrillation occurs, failure to prepare adequately for prompt initiation of cardiopulmonary bypass and venting of the left ventricle can be disastrous. In addition, antegrade root injection of cardioplegia is often ineffective. My personal bias is to forego this effort and simply open the aorta and simultaneously administer cardioplegia into both ostia. And we have not yet reached the point of making a decision about whether to repair or replace! Will repair provide adequate competence and defer the conduit clock of the Ross procedure until the child has grown? Does the Ozaki repair have a role in cases with disease limited to the leaflets? In cases in which repair is clearly not an option, the Ross procedure is certainly a reasonable option, but there are experienced surgeons who favor a homograft. In the background of this, we are cognizant that the decisions we make can affect not only survival, but the burden of reoperations for the lifetime of the patient.

\section{Reference}

1. Khoo B, Buratto E, Fricke TA, Gelbart B, Brizard CP, Brink J, et al. Outcomes of surgery for infective endocarditis in children: a 30-year experience. $J$ Thorac Cardiovasc Surg. 2019;158:1399-409. 